\title{
New Sealing Concept for Planar Solid Oxide Fuel Cells
}

\author{
K. Scott Weil, John S. Hardy, and Brian J. Koeppel
}

(Submitted January 16, 2006; in revised form May 22, 2006)

\begin{abstract}
A key element in developing high-performance planar solid oxide fuel-cell stacks is the hermetic seal between the metal and ceramic components. Two methods of sealing are commonly used: (a) rigid joining and (b) compressive sealing. Each method has its own set of advantages and design constraints. An alternative approach is currently under development that appears to combine some of the advantages of the other two techniques, including hermeticity, mechanical integrity, and minimization of interfacial stresses in the joint substrate materials, particularly the ceramic cell. The new sealing concept relies on a plastically deformable metal seal; one that offers a quasi-dynamic mechanical response in that it is adherent to both sealing surfaces, i.e., non-sliding, but readily yields or deforms under thermally generated stresses. In this way, it mitigates the development of stresses in the adjacent ceramic and metal components even when a significant difference in thermal expansion exists between the two materials. The preexperimental design of the seal, initial proof-of-principle results on small test specimens, and finite-element analyses aimed at scaling the seal to prototypical sizes and geometries are described herein.
\end{abstract}

Keywords bonded compliant seal, deformable metal foil, planar solid oxide fuel cells (pSOFC)

\section{Introduction}

One of the critical issues in designing and fabricating a high-performance planar solid oxide fuel cell (pSOFC) system is developing an appropriate means of hermetically sealing the metal and ceramic components in the stack. The functional requirements for pSOFC seals can be listed in one of four categories: (a) mechanical, (b) chemical, (c) electrical, and (d) fabrication. Within each group, a series of relevant material and design parameters can be established, as shown in Table 1. Ultimately, these parameters form the basis for a set of specifications, appropriate to a given pSOFC stack design that the seal must satisfy.

At present, essentially two standard methods of sealing are used: (a) forming a rigid joint or (b) constructing a compressive "sliding" seal. Each type of seal has its own set of advantages and design constraints. For example, rigid glass joining is a cost-effective and relatively simple method of bonding ceramic to metal. However, the softening point of the glass limits the maximum operating temperature to which the joint may be exposed. In addition, because the resulting glass-ceramic is a brittle material and forms a non-dynamic, low-yielding seal, it is imperative that the temperature-dependent coefficients of thermal expansion (CTE) of each joining component, i.e., the ceramic cell, the seal, and the metal separator, be approximately equal. If not, high thermal stresses can develop within the components during stack heat-up and/or cool-down, causing fracture of the cell or seal. Currently only a narrow range

This paper was presented at the ASM Materials Solutions Conference \& Show held October 18-21, 2004 in Columbus, OH.

K. Scott Weil, John S. Hardy, and Brian J. Koeppel, Pacific Northwest National Laboratory, Richland, WA 99352. Contact e-mail: scott.weil@pnl.gov. of high-temperature glass compositions within the borate- or phosphate-doped aluminosilicate families display CTEs that closely match those of the ferritic stainless steels commonly used in device separators and housings. Unfortunately, these glasses typically display signs of devitrification within the first few hours of exposure at operating temperature (Ref 1). As they begin to crystallize, their carefully engineered thermalexpansion properties change significantly, ultimately limiting the number of thermal cycles and the rate of cycling at which the resulting joints can survive.

Alternatively, in compressive sealing a compliant hightemperature material is captured between the two sealing surfaces and compressed, using a load frame external to the stack, to deliver hermetic sealing in the same way rubber gaskets are used in everyday appliances (Ref 2). Because the seal conforms to both sealing surfaces and is under constant compression during use, it forms a dynamic seal. That is, the sealing surfaces can slide past one another without disrupting the herme-

Table 1 Functional requirements and materials selection parameters of the SOFC seal

$\begin{array}{ll}\text { Mechanical } & \text { - Hermeticity } \\ & \text { - Ability to yield or deform to mitigate CTE mismatch } \\ & \text { stresses } \\ & \text { - Acceptable bonding strength or deformation under } \\ & \text { compressive loading } \\ \text { - High thermal cycle stability } & \\ \text { Chemical } & \text { Long-term chemical stability under simultaneous } \\ & \text { oxidizing/wet fuel environments } \\ & \text { - Long-term chemical compatibility with respect to the } \\ & \text { adjacent sealing surface materials } \\ \text { Electrical } & \text { Resistance to hydrogen embrittlement } \\ \text { Fabrication } & \text { Non-conductive } \\ & \text { - Low cost } \\ & \text { Facile processing and high reliability with respect to } \\ & \text { forming a hermetic seal } \\ & \text { Sealing conditions do not deleteriously affect the } \\ & \text { properties of the components or the performance of the } \\ & \text { stack }\end{array}$


ticity of the seal and CTE matching is not required between the ceramic cell and the metal separator. At present however, this technology remains incomplete due to lack of a reliable hightemperature sealing material that would form the basis of the compliant seal. A number of materials have been considered, including mica, nickel, and copper, but each has been found deficient for any number of reasons, ranging from oxidation resistance in the case of the metals to poor hermeticity and through-seal leakage with respect to the mica (Ref 2).

A third sealing alternative for pSOFCs is currently under development, i.e., the bonded compliant seal (BCS), which in concept incorporates the advantages of both rigid and compressive sealing. This design was anticipated to provide excellent hermeticity (comparable to that observed with glass-ceramic seals) and high mechanical integrity under thermal cycling and mechanical vibration (i.e., the seal is nonbrittle and quasidynamic), as well as mitigate any mismatch stresses that arise between adjacent components by "trapping" much of the stress as elastic or plastic strain within a thin, deformable sealing membrane. One of the primary advantages that this type of seal is expected to offer is that a much wider range of alloy compositions can be considered for use in the pSOFC interconnect. At present, the list of candidates is severely limited to those that exhibit good CTE matching with the ceramic cell, namely the chromia scale-forming ferritic stainless steels, which in general display significantly poorer mechanical, oxidation, and through-scale electrical properties than their nickel-based counterparts (Ref 3). However, for the bonded compliant seal concept to work, a number of issues will need to be addressed, including:

- Determining the appropriate oxidation-resistant, lowmodulus alloy for use in the foil membrane.

- Developing appropriate "adhesives" to bond the compliant metal seal to both faying surfaces.

- Defining the appropriate geometry of the seal to minimize the transfer of stresses from one component to the other.

- Ensuring that the seal is nonconductive (i.e., to eliminate shorting within the stack)

\section{Materials and Methods}

\subsection{Pre-experimental Design}

The BCS concept relies on a plastically deformable metal foil membrane; one that offers a quasi-dynamic mechanical response in that it is adherent to both sealing surfaces, i.e., nonsliding, but readily yields, or deforms, under thermally generated stresses. In this way, the seal mitigates the development of stresses in the adjacent ceramic and metal components. A room-temperature analogue of this concept is an elastomeric gasket coated on either side with a sticky adhesive such that the gasket bonds to both sealing surfaces. Because the gasket is made from a low-stiffness material, it readily deforms in response to stresses generated at the interfaces with the sealing surfaces, minimizing the transfer of stresses from one interface to the other. In the compliant seal design envisioned here, the stiffness of the seal is minimized not only by proper selection of the foil membrane material but also by appropriate geometric design of the membrane. A one-dimensional example of this is shown in Fig. 1. As the two substrates, Plate 1 and Plate 2, are heated, they expand at different rates (the two plates exhibit different CTEs). The C-shaped membrane accommodates this difference in expansion by readily deforming into an asymmet-

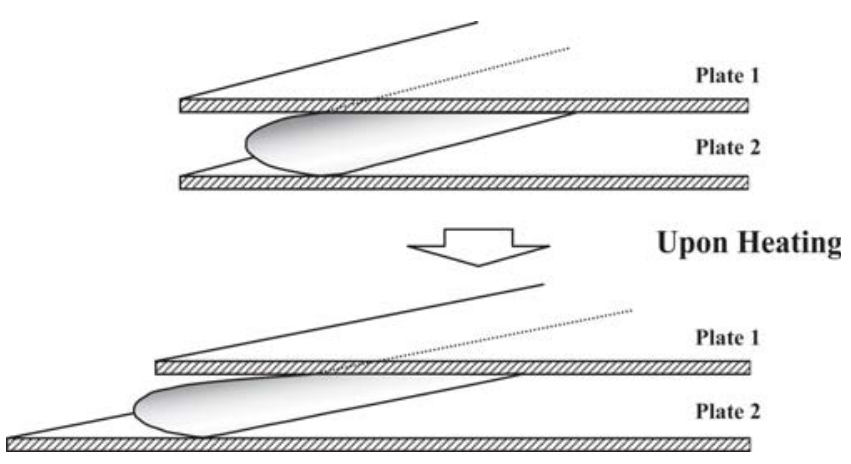

Fig. 1 Schematic of the thermomechanical response of a onedimensional compliant membrane seal upon heating

ric "C." Thus, the CTE mismatch between the two surfaces is effectively decoupled and neither sealing surface experiences the expansion strain of the other. With this in mind, the four issues outlined above were used as the basis for a proof-ofprinciple analysis: (a) membrane materials selection, (b) faying surface functionalization, (c) geometric design, and (d) electrical insulation.

2.1.1 Membrane Materials Selection. A number of hightemperature alloys that can potentially be considered in this application, including Ni- and Co-based superalloys and other $\mathrm{Al}$ - and/or Cr-containing nonferrous alloys; stainless steel and Fe-based superalloys; and noble metals such as $\mathrm{Ag}, \mathrm{Au}, \mathrm{Pd}$, and Pt. For the initial proof-of-concept development effort, materials selection focused on four key properties: high oxidation resistance, low stiffness, high ductility, and acceptable cost. Based on these factors, two families of alloys, the aluminum bronzes (or $\mathrm{Cu}-\mathrm{Al}$ alloys) and the Al-alloyed stainless steels (such as FeCrAlY) were selected for further study.

The alloys in both of these families contain Al in high enough concentration, typically $>3 \%$, that the oxidation resistance is improved many times over that of the non-Alcontaining parent material. This material property is particularly important in the present design due to the need for the material to be as thin as possible to concentrate mismatch and residual stresses way from the adjoining substrates, yet still exhibit low metal loss under high-temperature oxidizing conditions so that strength and long-term durability are retained. Using results from an initial screening analysis of the above materials (Ref 3), commercially available alumina-forming ferritic steel was chosen as the foil membrane: DuraFoil $(22 \% \mathrm{Cr}$, $7 \% \mathrm{Al}, 0.1 \% \mathrm{La}+\mathrm{Ce}$, bal. Fe; manufactured by Engineered Materials Solutions, Inc., Attleboro, MA).

2.1.2 Faying Surface Functionalization. The objective in this phase of the project is to demonstrate that the foil membrane can be hermetically joined to any of the ceramic faying surfaces in the joint, including the YSZ electrolyte layer on the cell and the alumina-based scale of the compliant foil or an intermediary oxide insulating layer. Advantage has been taken of a new brazing technique that has been previously used to successfully join FeCrAlY to $\mathrm{YSZ}$ and to $\mathrm{Al}_{2} \mathrm{O}_{3}$ (Ref 4, 5). The $\mathrm{Cu}-\mathrm{Ag}$ filler metal composition used in this braze is applied to the faying surface of the metal membrane via a thin-film deposition technique, such as PVD or electroplating. During heating in air to the melt temperature of the braze, the $\mathrm{Cu}$ oxidizes, then partially dissolves in the Ag, forming a homogeneous oxide-metal liquid that readily adheres to the oxide scale, which forms in situ on the foil, as well as on a wide variety of other ceramic surfaces. Preliminary studies have shown that, 


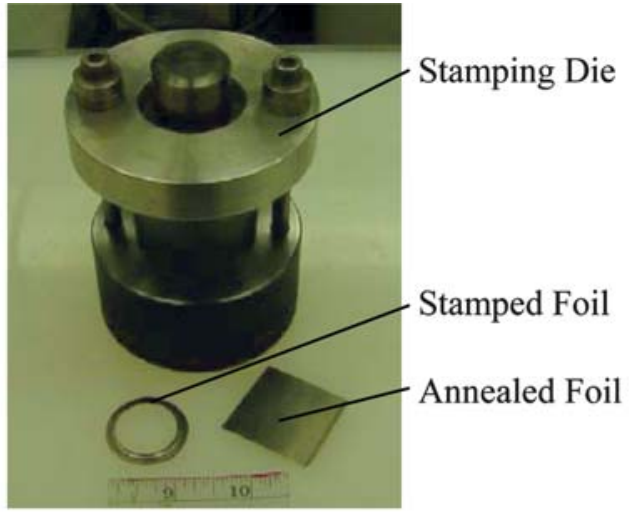

(a)

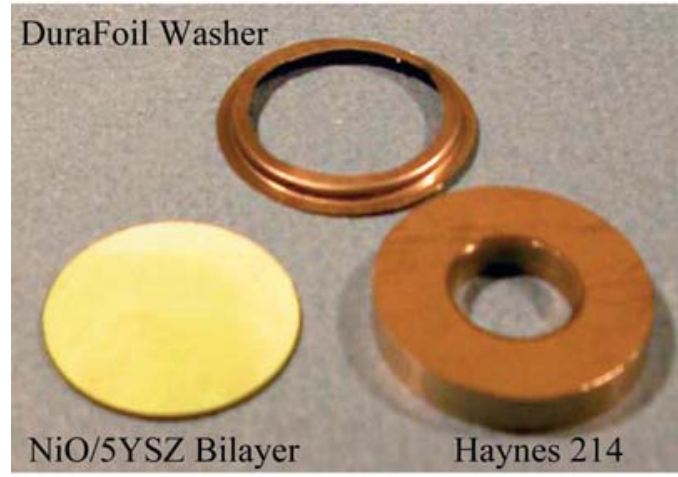

(b)

Fig. 2 (a) Stamping die and (b) sealing specimen components used in fabricating the foil seals

when the composition of this braze material is properly adjusted, a high-strength, hermetic bond can be achieved (Ref 6).

2.1.3 Geometric Design. The seal design that is currently being used in proof-of-principle testing is a $25 \mathrm{~mm}$ diameter stamped ring that exhibits a simple S-shaped geometry in cross-section. As will be discussed, finite element modeling has been used to determine if this geometry can be scaled to more prototypical sizes, i.e., $120 \times 120 \mathrm{~mm}$.

2.1.4 Electrical Insulation. Efforts at incorporating an appropriate electrical insulator into this seal design are still in the initial stages. The use of thin alumina and zirconia-toughened alumina (ZTA) faying surface coatings are currently being investigated as potential candidates. ZTA appears particularly promising not only because it is an electrical and ionic insulator at the operating temperature, but also because the CTE is high enough to sufficiently match that of the candidate membrane materials. It also offers good mechanical toughness and thermal shock resistance. The $\mathrm{CuO}-\mathrm{Ag}$ filler metal alloy, previously mentioned, readily wets both $\mathrm{Al}_{2} \mathrm{O}_{3}$ and ZTA, so the use of either material appears viable from this standpoint.

\subsection{Proof-of-Principle Testing}

2.2.1 Materials. The DuraFoil was supplied as a $50 \mu \mathrm{m}$ thick sheet. It was sheared into $3 \times 3 \mathrm{~cm}$ coupons, annealed in vacuum at $900{ }^{\circ} \mathrm{C}$ for $2 \mathrm{~h}$, and stamped into cap-shaped washers using a die designed specifically for this purpose, as shown in Fig. 2(a) and (b). The stamped foils were ultrasonically cleaned in soap and water, then flushed with acetone to remove the lubricant from the stamping operation.

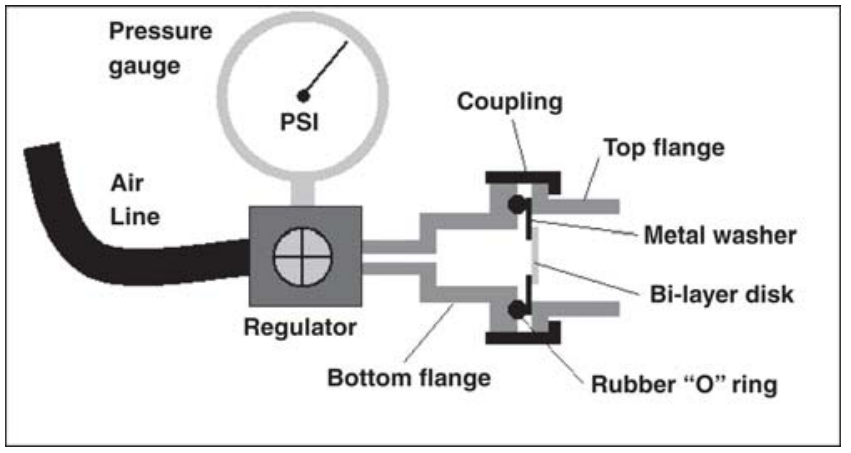

Fig. 3 Rupture strength test schematic

Each foil washer was bonded to a NiO-5YSZ bilayer disc that was prototypical in composition, layer thickness, and material density to the anode-supported membranes commonly used in mid-temperature pSOFC stacks. Formed by tape casting and lamination, the $\mathrm{NiO}$ and 5YSZ layers were approximately 600 and $7 \mu \mathrm{m}$ thick, respectively, while the overall sintered discs measured $\sim 25 \mathrm{~mm}$ in diameter. The other substrate to which the foil seal was bonded was a $6.2 \mathrm{~mm}$ thick Haynes 214 washer with an outer diameter of $44 \mathrm{~mm}$ and an inner diameter of $15 \mathrm{~mm}$. As an alumina-scale forming nickel-based superalloy, Haynes 214, displays excellent oxidation resistance at temperatures in excess of $1000{ }^{\circ} \mathrm{C}$ but also exhibits an average CTE of 15.7 $\mu \mathrm{m} / \mathrm{m} \cdot \mathrm{K}$, which is nearly $50 \%$ higher than that of the anodesupported bilayer $(\mathrm{CTE}=10.6 \mu \mathrm{m} / \mathrm{m} \cdot \mathrm{K})$. The stamped DuraFoil component was joined to the Haynes 214 washer using BNi-2 braze tape (Wall Colmonoy, Inc., Madison Heights, MI). A second brazing operation using the in-house prepared braze, $4 \mathrm{~mol} \% \mathrm{CuO}$ in $\mathrm{Ag}$ ( $\operatorname{Ref} 5$ ), was conducted at $1000{ }^{\circ} \mathrm{C}$ in air for 15 min to join the top side of the foil to the YSZ side of the ceramic bilayer disc, thereby forming the test specimen.

2.2.2 Testing and Characterization. Rupture strength testing was used to facilitate quantitative comparison of the RAB seal joint strengths (Ref 7). Figure 3 shows a schematic of the rupture test equipment. The test sample is placed within a fixture that consists of a bottom and top flange, a coupling that secures and centers the two flanges, and an O-ring that is squeezed against the bottom surface of the Haynes 214 washer. Compressed air was used to pressurize the back side of the washer specimen up to a maximum rated pressure of $1 \mathrm{MPa}$. A digital regulator allows the pressure behind the joined bilayer disk to be slowly increased to a given set point. The volume of compressed gas can be isolated between the specimen and valve, making it possible to identify a leak in the seal by any decay in pressure. In this way, the device can be used to measure the hermeticity of a given seal configuration without causing destructive failure of the seal. Alternatively, by increasing the pressure to the point of specimen rupture, the maximum pressure that the specimen can withstand may be measured. Thermal cycle testing was performed by heating the specimens in air to $750{ }^{\circ} \mathrm{C}$ in $10 \mathrm{~min}$ using an infrared (IR) furnace, holding at temperature for $10 \mathrm{~min}$, and cooling to $\leq 70{ }^{\circ} \mathrm{C}$ in $40 \mathrm{~min}$ before reheating under the same conditions for a given number of cycles. A minimum of six specimens was tested for each test condition. Microstructural analysis of the joints was conducted on polished cross-sectioned samples using a JEOL JSM-5900LV scanning electron microscope (SEM) equipped with an Oxford energy-dispersive x-ray analysis (EDX) system that employs a windowless detector. 


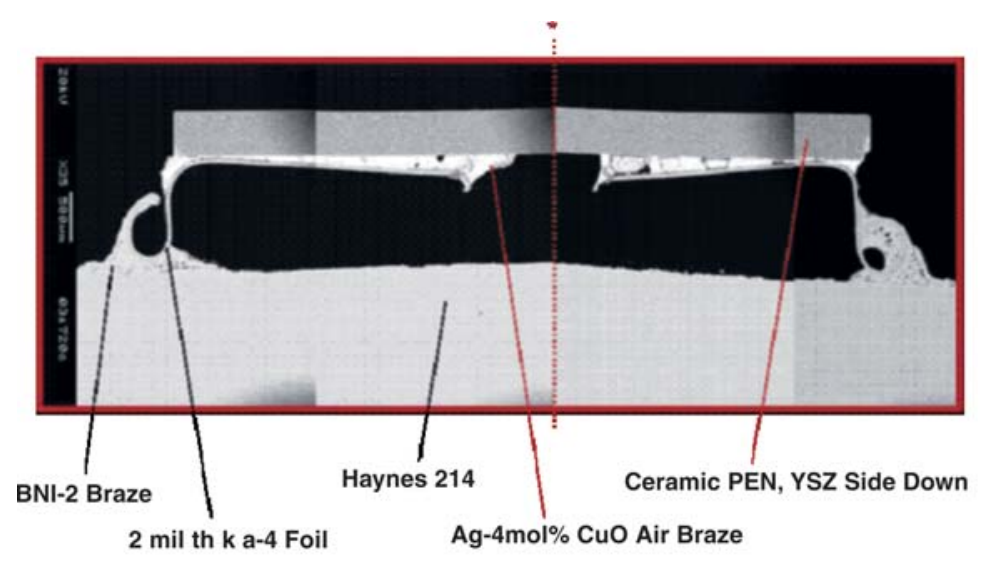

*Mid-section of the specimen not shown.

(a)

Fig. 4 (a) Composite cross-sectional micrograph of an as-joined rupture test specimen; (b) schematic of the bonded compliant sealing concept in use in the pSOFC gas manifold sealing

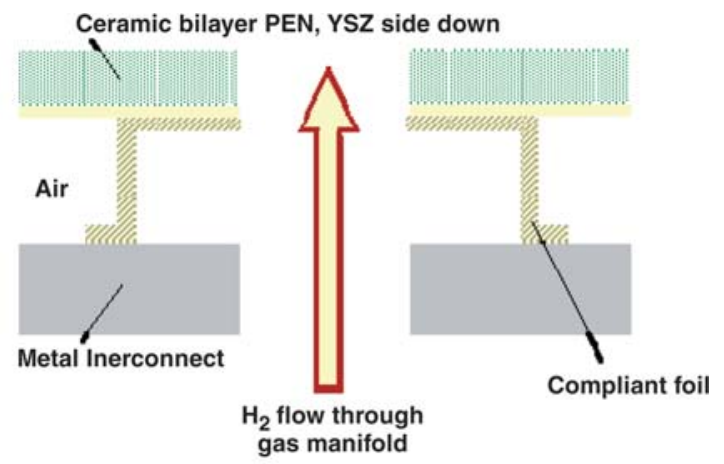

(b)

(a)

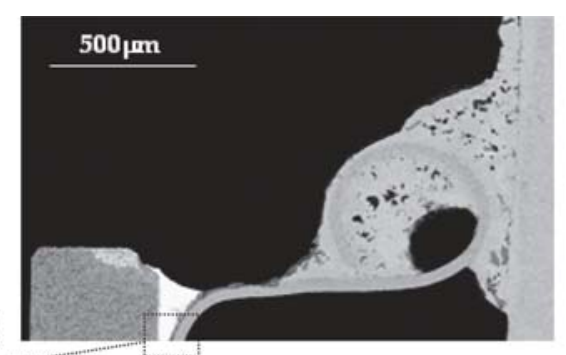

(b)

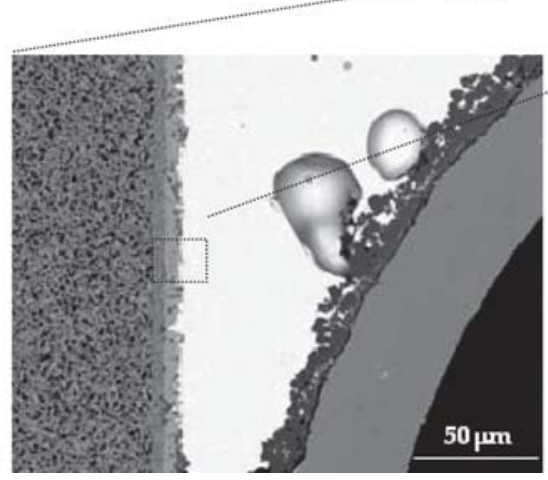

(c)

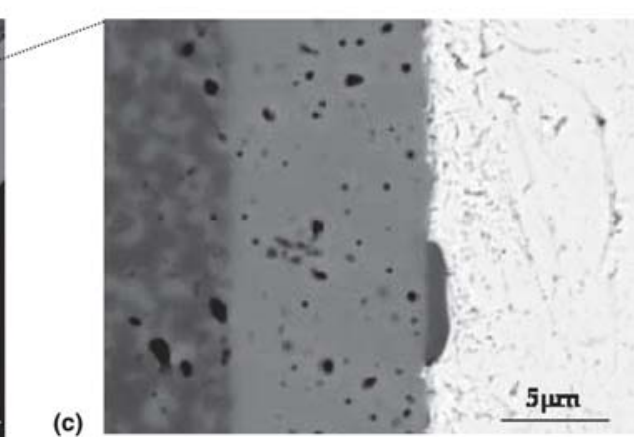

Fig. 5 Cross-sectional SEM micrographs of the YSZ-silver braze region of an as-sealed rupture specimen at the following original magnifications: (a) $52 \times$ (b) $450 \times$ and (c), $4000 \times$

\section{Proof-of-Principle Results}

Shown in Fig. 4(a) is a composite cross-sectional micrograph of an as-joined rupture specimen. The sample was well sealed, as determined by hermeticity testing conducted prior to metallography. The entire seal is approximately $1.1 \mathrm{~mm}$ thick, although it is expected that this can be readily reduced simply by altering the geometry of the DuraFoil stamping. As seen in the sequence of higher-magnification micrographs in Fig. 5 (a) to (c), the two brazes each account for 50-100 $\mu \mathrm{m}$ of the overall seal thickness. Also apparent from Fig. 4(a) are changes to the geometry of the foil washer that occurred during joining. For example, the BNi-2 braze causes the outer periphery of the foil to curl due to a mismatch in CTE between the two mate- rials. Although this does not degrade the performance of the rupture test specimen, it may affect the performance of the seal in the stack. A conceptual drawing of the seal in an actual application is shown in Fig. 4(b). Sealing occurs around the gas manifold holes incorporated into both the cell and separator plate.

On the ceramic side of the seal, the Ag braze region is thicker in-board of the specimen than out. As seen in Fig. 5(b) and (c), this filler metal appears to form a robust joint between the 5YSZ and the alumina scale of the DuraFoil. Although EDX analysis shows no indication of a reaction zone at the 5YSZ/filler metal interface, a 10-15 $\mu \mathrm{m}$ thick zone appears to have formed on the DuraFoil due to reaction between the $\mathrm{Al}_{2} \mathrm{O}_{3}$ scale and the $\mathrm{CuO}$ in the braze. The dominant product in this interfacial region is a mixed oxide phase, $2 \mathrm{CuO} \cdot \mathrm{Al}_{2} \mathrm{O}_{3}$. 
Results from rupture strength testing of the sealed specimens are shown in Fig. 6. All of the tested specimens were found to be hermetic up to the maximum pressure $(415 \mathrm{kPa})$ tested during initial leak testing. More extensive pressure testing up to the point of rupture indicated no failure in any of the seals, even in the specimens that underwent as many as 20 rapid thermal cycles. Instead in each case, failure occurred within the center of the ceramic disc (of the type shown in the inset in Fig. 6), revealing this as the weakest component in the current specimen configuration. The corresponding range of rupture strength values, indicated by the shaded region in Fig. 6 , are the effective pressures at which failure is expected to

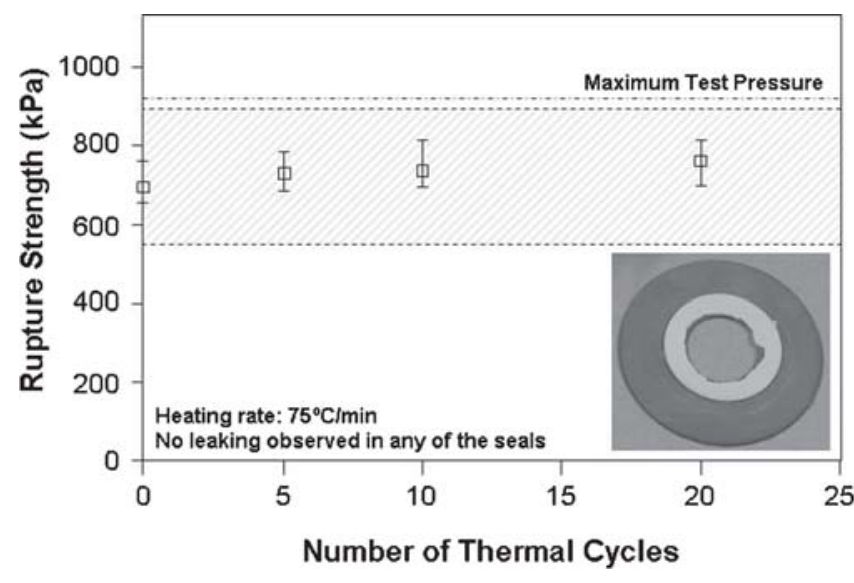

Fig. 6 Rupture strength of the bonded compliant joint specimens in the as-joined and as-cycled conditions. (Inset) Typical mode of failure observed in the rupture specimens, within the center of the ceramic disc

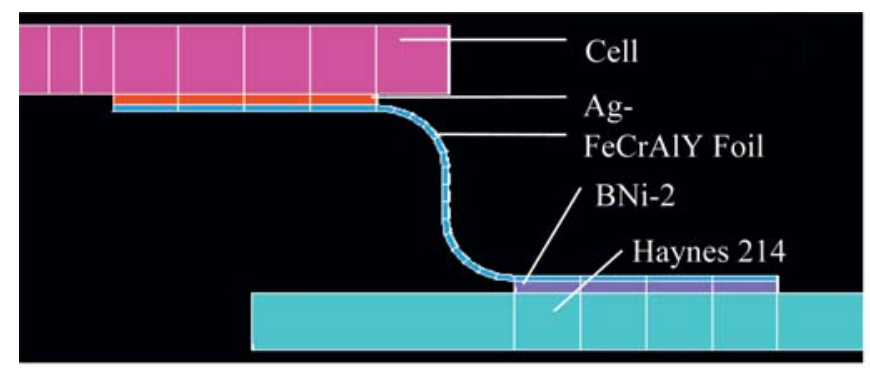

(a) occur in the cell based on 4-point bend strength testing (Ref 7). By way of comparison, similar rupture specimens constructed of the same NiO/5YSZ bilayer discs joined directly to $300 \mu \mathrm{m}$ thick 430SS washers using a typical barium calcium aluminosilicate pSOFC sealing glass displayed an average strength of only $72 \mathrm{kPa}$ in the as-joined condition, which degraded to nearly zero upon rapid thermal cycling out to 10 cycles (Ref 7). Failure in these glass-sealed specimens occurs along the interface between the sealing glass and the 430SS.

\section{Finite-Element Analysis}

Finite-element analysis was used to evaluate the feasibility of scaling this sealing concept from the initial $25 \mathrm{~mm}$ diameter proof-of-principle specimen to a $120 \times 120 \mathrm{~mm}(10 \mathrm{~mm}$ radii corners) full-scale component. Specifically, the states of stress in the cell, the foil, and the underlying frame were determined, as were the stress states in both brazes, and these were compared with the fracture and/or yield stresses in the corresponding materials. The dimensions and material properties used in modeling the seal configuration are listed in Table 2. The ANSYS 8.0 software suite was used in the modeling analysis. Figure 7(a) shows a cross-section of the seal, with each component labeled. Displayed in Fig. 7(b) is a quarter-symmetry model of the sealed cell. Figure 7(c) shows the tensile stress contours predicted by the model upon thermal cycling from an operating temperature of $750{ }^{\circ} \mathrm{C}$ to room temperature, which outside of an independent applied mechanical stress, is the largest stress state expected in this system. The corresponding color chart given on the right-hand side of Fig. 7(c) is in MPa.

Note that the largest stress (denoted by the light blue and aqua blue colors) is concentrated within the metal foil, as

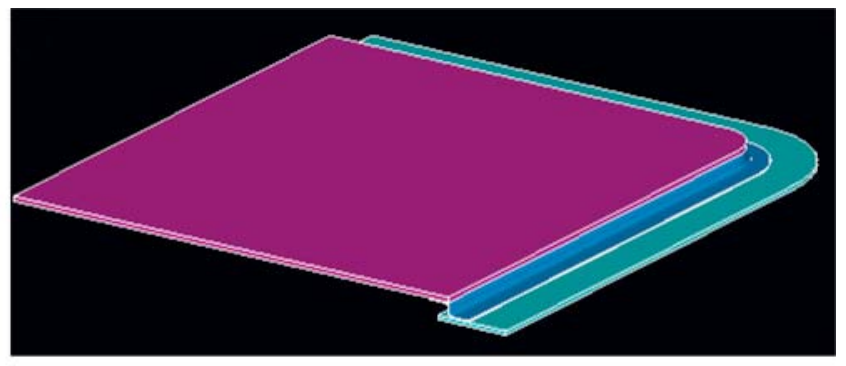

(b)

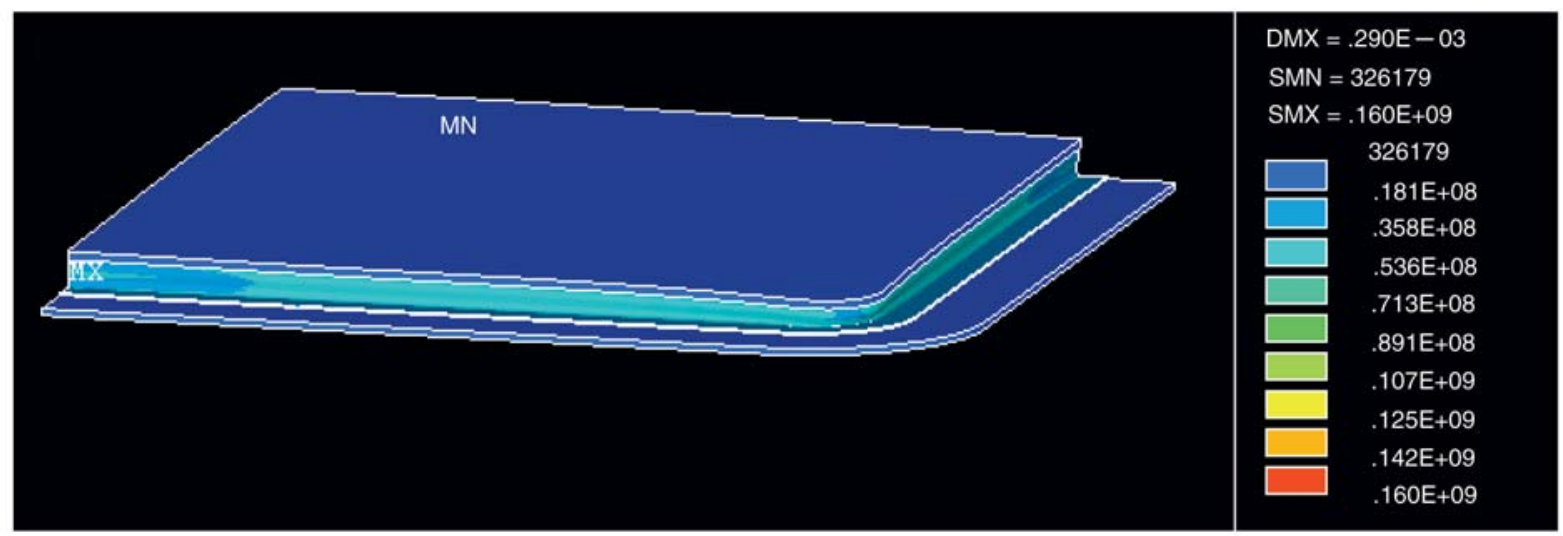

(c)

Fig. 7 Finite-element modeling: (a) cross section of the bonded compliant seal model, (b) quarter-symmetry model for the cell attached to a Haynes 214 frame via a bonded compliant seal, and (c) corresponding tensile stress contours for the quarter symmetry model 
Table 2 Component dimensions and materials database properties employed in modeling

\begin{tabular}{lcl}
\hline Component & Thickness, $\boldsymbol{\mu m}$ & \multicolumn{1}{c}{ Material } \\
\hline Cell & 600 & Ni-YSZ/YSZ \\
Cell-to-foil braze & 100 & Ag-4mol\%CuO \\
Metal foil & 50 & FeCrAlY \\
Foil-to-frame braze & 100 & BNi-2 braze \\
Frame & 500 & Haynes 214 \\
\hline
\end{tabular}

hoped for originally. In fact, finite-element results indicate that the ceramic cell experiences a tensile stress that is approximately one-tenth of its maximum strength (Ref 8), the Haynes 214 experiences a maximum stress that is less than 1/100th that required for yielding, and the foil experiences a maximum stress (at the corners) that is approximately $70 \%$ of its yielding stress at room temperature. Thus, initial analysis suggests that the present design appears to be scaleable. However, note that the corner of the cell does appear to bend downward slightly. This may be a cause for concern, given the brittle nature of the cell. Modeling is continuing in an effort to determine how individual cells deform in a multicell stack, where additional geometric and mechanical constraints apply.

\section{Summary and Conclusion}

One of the major challenges remaining before pSOFCs can be commercialized is developing a robust cell-to-separator seal that maintains its hemeticity under varied operating conditions over the lifetime of the stack. Of particular interest is designing a seal that allows the use of more robust, but also higher CTE, Ni-based superalloys in the separator plate. In this regard, work on a new pSOFC sealing concept, the bonded compliant seal, shows some promise. In its present embodiment, a thin, oxidation-resistant metal foil is used as an elasto-plastically deformable membrane that when bonded to the ceramic cell and metal separator forms a hermetic seal. Aggressive thermal cycle testing indicates that this seal retains its original hermeticity and bond strength, even when it is used to join materials with a significant difference in thermal expansion behavior. Initial finite-element modeling suggests that this sealing concept is scaleable to larger sizes and different planar geometries, although additional work is needed to verify these results.

\section{Acknowledgments}

The authors thank Nat Saenz, Shelly Carlson, and Jim Coleman for their assistance in sectioning and polishing the popgun samples and conducting the metallographic and SEM analysis work. This work was supported by the U.S. Department of Energy, Office of Fossil Energy, SECA SOFC Program. The Pacific Northwest National Laboratory is operated by Battelle Memorial Institute for the United States Department of Energy (U.S. DOE) under Contract DE-AC06-76RLO 1830.

\section{References}

1. S.-B. Sohn, S.-Y. Choi, G.-H. Kim, H.-S. Song, and G.-D. Kim, Stable Sealing Glass for Planar Solid Oxide Fuel Cells, J. Non-Cryst. Solids, 2002, 297, p 103-112

2. S.P. Simner and J.W. Stevenson, Compressive Mica Seals for SOFC Applications, J. Power Sources, 2001, 102, p 310-316

3. Z.G. Yang, K.S. Weil, D.M. Paxton, and J.W. Stevenson, Selection and Evaluation of Heat-Resistant Alloys for SOFC Interconnect Applications, J. Electrochem. Soc., 2003, 150, p A1188-A1201

4. J.S. Hardy, J.Y. Kim, and K.S. Weil, Joining Mixed Conducting Oxides Using an Air-Fired Electrically Conductive Braze, J. Electrochem. Soc., 2004, 151, p J43-J49

5. K.S. Weil, J.Y. Kim, and J.S. Hardy, Reactive Air Brazing: A Novel Method of Sealing SO-TCS and Other Solid-State Electrochemical Devices, Electrochem. Solid State Lett., 2005, 8(2), p A133-A136

6. J.Y. Kim, J.S. Hardy, and K.S. Weil, Novel Metal-ceramic Joining for Planar SOFCs, J. Electrochem. Soc., 2005, 152(6), p J52-J56

7. K.S. Weil, J.E. Deibler, J.S. Hardy, D.S. Kim, G.G. Xia, L.A. Chick, and C.A. Coyle, Rupture Testing as a Tool for Developing Planar Solid Oxide Fuel Cell Seals, J. Mater. Eng. Perf., 2004, 13, p 316-326

8. S. Mukerjee, S.J. Shaffer, J. Zizelman, L.A. Chick, S. Baskaran, Y. Chou, C.A. Coyle, J.E. Deibler, G.D. Maupin, K.D. Meinhardt, et al., Proc. of the 8th Int. Symp. on Solid Oxide Fuel Cells, Vol. 2003-07, The Electrochemical Society, Pennington, NJ, 2003, p 88 